\title{
Developmental exposure to a complex PAH mixture causes persistent behavioral effects in naive Fundulus heteroclitus (killifish) but not in a population of PAH-adapted killifish
}

\author{
D.R. Brown ${ }^{\text {a,* }}$, J.M. Bailey ${ }^{\text {b }}$, A.N. Oliveri ${ }^{\text {b }}$, E.D. Levin ${ }^{\text {a,b }}$, R.T. Di Giulio ${ }^{\text {a }}$ \\ a Nicholas School of the Environment, Duke University, Durham, NC 27514, USA \\ b Duke University Medical Center, Duke University, Durham, NC 27514, USA
}

\section{A R T I C L E I N F O}

\section{Article history:}

Received 29 June 2015

Received in revised form 26 October 2015

Accepted 31 October 2015

Available online 6 November 2015

\section{Keywords:}

Polycyclic aromatic hydrocarbons (PAHs)

Behavior

Locomotion

Subteratogenic

Adaptive costs

Fundulus heteroclitus

\begin{abstract}
A B S T R A C T
Acute exposures to some individual polycyclic aromatic hydrocarbons (PAHs) and complex PAH mixtures are known to cause cardiac malformations and edema in the developing fish embryo. However, the heart is not the only organ impacted by developmental PAH exposure. The developing brain is also affected, resulting in lasting behavioral dysfunction. While acute exposures to some PAHs are teratogenically lethal in fish, little is known about the later life consequences of early life, lower dose subteratogenic PAH exposures. We sought to determine and characterize the long-term behavioral consequences of subteratogenic developmental PAH mixture exposure in both naive killifish and PAH-adapted killifish using sediment pore water derived from the Atlantic Wood Industries Superfund Site. Killifish offspring were embryonically treated with two low-level PAH mixture dilutions of Elizabeth River sediment extract (ERSE) (TPAH $5.04 \mu \mathrm{g} / \mathrm{L}$ and $50.4 \mu \mathrm{g} / \mathrm{L}$ ) at $24 \mathrm{~h}$ post fertilization. Following exposure, killifish were raised to larval, juvenile, and adult life stages and subjected to a series of behavioral tests including: a locomotor activity test (4 days post-hatch), a sensorimotor response tap/habituation test ( 3 months post hatch), and a novel tank diving and exploration test ( 3 months post hatch). Killifish were also monitored for survival at 1, 2, and 5 months over 5-month rearing period. Developmental PAH exposure caused short-term as well as persistent behavioral impairments in naive killifish. In contrast, the PAH-adapted killifish did not show behavioral alterations following PAH exposure. PAH mixture exposure caused increased mortality in reference killifish over time; yet, the PAH-adapted killifish, while demonstrating long-term rearing mortality, had no significant changes in mortality associated with ERSE exposure. This study demonstrated that early embryonic exposure to PAH-contaminated sediment pore water caused long-term locomotor and behavioral alterations in killifish, and that locomotor alterations could be observed in early larval stages. Additionally, our study highlights the resistance to behavioral alterations caused by low-level PAH mixture exposure in the adapted killifish population. Furthermore, this is the first longitudinal behavioral study to use killifish, an environmentally important estuarine teleost fish, and this testing framework can be used for future contaminant assessment.
\end{abstract}

(c) 2015 Elsevier Inc. All rights reserved.

\section{Introduction}

Polycyclic aromatic hydrocarbons (PAHs) are ubiquitous in the environment and concentrations increase with human population growth and fossil fuel use (Van Metre et al., 2000; Foan et al., 2010; Yang et al., 2011). Aquatic environments are susceptible to PAH contamination in a variety of ways including oil shipping, oil refining, industrial outfall, wastewater discharges, urban runoff, and atmospheric deposition (Van Metre et al., 2000; Walker et al., 2004; Van Metre and Mahler, 2005; Hylland, 2006). Anthropogenic PAHs are present in the environment as complex mixtures, and the composition is in part dependent on the contribution from pyrolytic and/or petrogenic sources

\footnotetext{
* Corresponding author.

E-mail address: daniel.r.browndu@gmail.com (D.R. Brown).
}

(Van Metre et al., 2000; Van Metre and Mahler, 2005). Pyrolytic PAH mixtures are composed of predominantly high molecular weight (HMW) PAHs such as benzo[a]pyrene (BaP), whereas petrogenic PAHs contain lower concentrations of HMW PAHs (Shen et al., 2013).

PAHs are hydrophobic, and consequently, associated with suspended particulate matter in water or settle into sediments (Benlahcen et al., 1997; Baumard et al., 1998; Cachot et al., 2006, 2007; Hylland, 2006). Aquatic sediments constitute a major sink for hydrophobic pollutants, and studies show PAHs can be persistent in sediments over time (Cachot et al., 2006, 2007; Hylland, 2006; Yanagida et al., 2012). For this reason, sediments represent a significant source of exposure for fish embryos (Benlahcen et al., 1997; Baumard et al., 1998; Cachot et al., 2006, 2007). Fish in both freshwater and marine ecosystems will commonly lay their eggs on sediments or gravel found in river or seabed (Baumard et al., 1998; Cachot et al., 2006, 2007). Several 
minnow species are known to bury eggs in sediment (Skinner et al., 2005; Burnett et al., 2007). It is well known that PAHs can transfer through the chorion of the fish embryos (Djomo et al., 1996; Hornung et al., 1996; McElroy et al., 2006). Therefore, it is likely that fish embryos developing on $\mathrm{PAH}$-contaminated sediment and other polluted sediments will be exposed during sensitive ontogenetic time points.

The Elizabeth River (ER) is a highly contaminated subestuary of the Chesapeake Bay watershed, located in the Tidewater region of southeastern Virginia, USA (Walker et al., 2004). Several former wood treatment industries contaminated areas of the river with creosote, a complex mixture of chemicals consisting primarily of unsubstituted polycyclic aromatic hydrocarbons (PAHs) and some heterocyclic and phenolic PAHs (Clark et al., 2013; Fang et al., 2014). Total PAH concentrations at one of the major sites, Atlantic Wood Industries (AW), range from 100 to $500 \mu \mathrm{g} / \mathrm{g}$ in dry sediment (Mulvey et al., 2002; Walker et al., 2004). Sediment pore water from the site has recently been chemically characterized (Fang et al., 2014). The AW site was placed on the Environmental Protection Agency's "National Priorities List" (for Superfund sites) in 1990, and is currently being remediated.

A large number of organic xenobiotics, e.g., dioxins, PCBs, and polybrominated diphenyl ether (PBDE) have been reported to disrupt embryonic development in fish (Cantrell et al., 1996; Henry et al., 1997; Carls et al., 1999; Heintz et al., 1999; Barron et al., 2004; Antkiewicz et al., 2005; Carney et al., 2006; Incardona et al., 2006; Carls et al., 2008). These teratogenic effects have also been reported for individual PAHs and PAH mixtures, and some exposures at environmentally relevant concentrations cause early life stage toxicity (Moles and Rice, 1983; Incardona et al., 2006, 2009, 2011). Acute PAH toxicity manifests as cranio-facial and cardiac malformations and pericardial and yolk sac edema that is similar to effects seen with some dioxinlike compounds (DLCs), 2,3,7,8-tetrachlorodibenzo-p-dioxin (TCDD), and 3,3',4,4',5-pentachlorobiphenyl (PCB-126) (Helder, 1981; Spitsbergen et al., 1991; Walker and Peterson, 1991; Walker et al., 1991).

Fundulus heteroclitus (the Atlantic killifish or mummichog; hereafter referred to as killifish) is a small teleost fish found in Atlantic coastal estuaries from Newfoundland to Florida (Kneib, 1986; Teo and Able, 2003). They are the most abundant intertidal fish species and a major component of food webs in these estuaries. Although killifish are widely distributed, individuals have relatively small home ranges (Lotrich, 1975; Skinner et al., 2005). This high site fidelity and small migration area makes them ideal for studying the effects of anthropogenic contamination and other environmental stressors (Burnett et al., 2007). The killifish inhabiting the AW Superfund site are chronically exposed to PAH-contaminated sediments, but have developed significant resistance to the acute cardiotoxicity and other teratogenic effects of Elizabeth River sediments, PAHs, PCB-126, and several pesticides (Meyer and Di Giulio, 2002; Meyer et al., 2002; Ownby et al., 2002; Clark and Di Giulio, 2012; Clark et al., 2013). Recent studies have also noted other populations of killifish residing throughout the Elizabeth River and their relative resistance and susceptibility to PAH cardiotoxicity and other environmental contaminants (Clark and Di Giulio, 2012; Clark et al., 2013).

In the current study, we focused on the later life behavioral impacts of early developmental exposure to a complex PAH mixture with particular emphasis placed on the comparison between two different populations of killifish. We hypothesized that early embryonic exposure to low dilutions of ERSE would alter larval locomotor activity of the naive King's Creek killifish (KC) (King's Creek is a relatively uncontaminated tributary of the Severn River, VA), but would not alter locomotor activity in the PAH-adapted Atlantic Wood killifish (AW) population. In addition, we postulated that KC killifish exposed to higher dilutions of ERSE would experience increased mortality over time, whereas AW killifish would experience little to no increases in mortality due to their PAH-resistance. To this end, we exposed both the naïve reference KC population of killifish and the PAH-adapted AW killifish to subteratogenic dilutions (dilutions that did not cause overt cardiac abnormalities) of ERSE. After early embryonic exposure to low dilutions of ERSE, larvae were tested for mobility and then raised to three months for additional behavioral testing (startle habituation assay and predator avoidance/novel dive assay). In a separate set of experiments, killifish were treated similarly and raised to 5 months for mortality assessment.

While studies have described the developmental effects of acute individual and mixed PAH exposure, very few studies have examined the later life consequences of early life PAH exposures, particularly alterations to fish behavior (Vignet et al., 2014a, 2014b). Additionally, there are several tools and assays available for the zebrafish (Danio rerio) model, (Bailey et al., 2013), but few studies have employed these tests to evaluate how early life exposure to PAH mixtures impacts later life behavioral outcomes in a more environmentally relevant model such as the killifish. Little is known about the performance and behavioral costs that may be associated with being a PAH-adapted AW killifish.

\section{Methods}

\subsection{Adult fish care}

Adult killifish from the PAH-adapted AWI population in the Elizabeth River were collected with wire mesh minnow traps at the Atlantic Wood Industries Superfund Site $\left(36^{\circ} 48^{\prime} 27.2^{\prime \prime} \mathrm{N}, 76^{\circ} 17^{\prime} 38.1^{\prime \prime} \mathrm{W}\right)$. Adult killifish from a reference population were collected from King's Creek, a relatively uncontaminated tributary of the Severn River in Virginia, USA $\left(37^{\circ} 18^{\prime} 16.2^{\prime \prime} \mathrm{N}, 76^{\circ} 24^{\prime} 58.9^{\prime \prime} \mathrm{W}\right)$. In the laboratory, adults were maintained in flow-through systems consisting of a series of 30- or 40-1 tanks containing 15\% artificial sea water (ASW; Instant Ocean, Foster and Smith, Rhinelander, WI, USA). The system was maintained at $25-28{ }^{\circ} \mathrm{C}$ on a $14: 10 \mathrm{~h}$ light/dark cycle. Adults were fed pelleted feed ad libitum (Aquamax® Fingerling Starter 300; PMI Nutritional International, LLC, Brentwood, MO, USA). Eggs were obtained by manual spawning of females and fertilized in vitro by expressing sperm from males into a beaker containing eggs in ASW. Following spawning, embryos were set aside for a minimum of $1 \mathrm{~h}$ to allow fertilization, then washed briefly with $0.3 \%$ hydrogen peroxide solution.

F1 Atlantic Wood embryos were collected following mixed breedings of approximately 100 females and 20 males. Each breeding generated several thousand eggs and approximately 500 were maintained per Petri dish (VWR International, West Chester, PA, USA) lined with absorbent filter paper (No. 3MM chromatography paper; Whatman International Ltd., Maidstone, England). ASW was added to the dishes to keep the eggs moist but not completely submerged.

Embryos were screened at $24 \mathrm{~h}$ post fertilization (hpf) for proper development. All screened embryos used in all experiments were exposed to ERSE at $24 \mathrm{hpf}$ in $10 \mathrm{~mL}$ of dosing solution in $20 \mathrm{~mL}$ glass scintillation vials (VWR, West Chester, PA). Embryos were exposed individually in scintillation vials $(n=1)$. Embryos with identical treatments within a particular experiment were considered treatment replicates, and all experiments were replicated a minimum of two times. A range of ERSE dilutions (Control, $0.1 \%, 1 \%, 2 \%, 3 \%, 5 \%, 10 \%, 20 \%, 25 \%$, and 50\%) were used for initial cardiac teratogenicity screening and two subteratogenic dilutions, $0.1 \%$ and $1.0 \%$ ERSE (TPAH $5.04 \mu \mathrm{g} / \mathrm{L}$ and $50.4 \mu \mathrm{g} / \mathrm{L}$ respectively), were selected for long-term rearing studies to characterize later life mortality and behavioral outcomes (Fig. 1). KC ERSE range dilutions ended at $5 \%$ because all embryos demonstrated overt cardiac teratogenesis; whereas, dilution ranges were expanded for the PAH-resistant AW population. The chemical characterization of ERSE and specific PAH concentrations can be found in Fang et al. (2014). ERSE exposure lasted until $144 \mathrm{hpf}$ at which time embryos were screened for cardiac abnormalities via a semi-quantitative scoring system. After screening, F1 embryos that did not have overt cardiac abnormalities were transferred to absorbent filter paper and maintained at $27{ }^{\circ} \mathrm{C}$ in an incubator until 14 days pf. At day 14 , ASW was added to the Petri dishes, the absorbent 


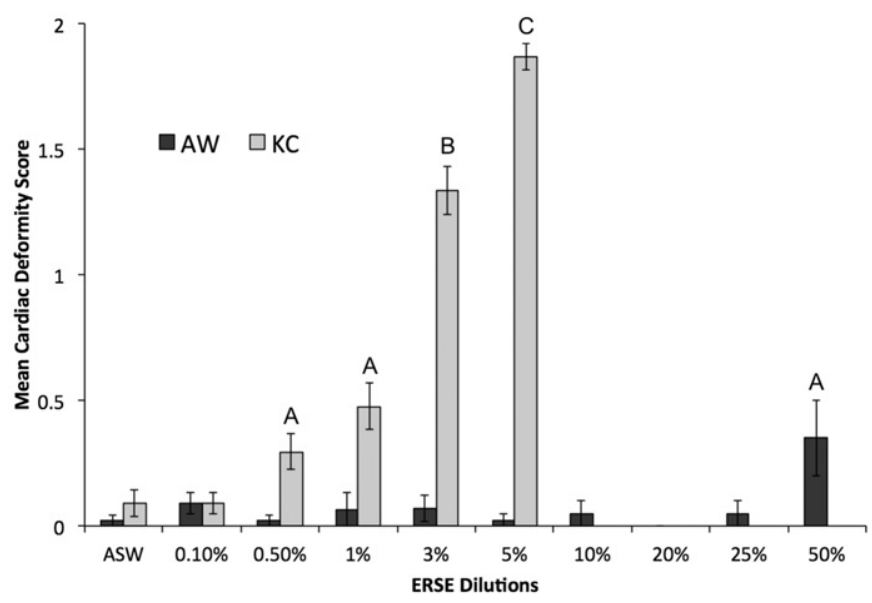

Fig. 1. Semi-quantitative cardiac deformity screen in King's Creek and Atlantic Wood F. heteroclitus exposed to dilutions of Elizabeth River sediment extract. The graph shows the cardiac deformity score observed at $144 \mathrm{~h}$ post fertilization (hpf) for ERSE exposed killifish embryos. KC (gray bar) and AW (dark gray bar) killifish populations were exposed ERSE dilutions at $24 \mathrm{hpf}$. Each bar represents the mean deformity score for three experiments with ten killifish per treatment ( total $\mathrm{n}=30$ ). Letters indicate significant difference $(\mathrm{p} \leq 0.05)$ compared to artificial saltwater (ASW) controls.

paper was removed, and the dishes were gently rocked in a shaker until larvae hatched. Hatched larvae were separated for larval testing and long-term rearing. Long-term reared killifish larvae were maintained in a $27^{\circ} \mathrm{C}$ incubator in 2-1 beakers and fed a diet of brine shrimp and gradually transitioned to a mix of Ziegler's Adult Zebrafish Complete Diet (Aquatic Habitats, Apopka, FL, USA) and Cyclop-eeze (Argent Chemical Laboratories, Redmond, WA, USA). After 1-week in the incubator, these larvae were transferred from beakers and were maintained at $28{ }^{\circ} \mathrm{C}$ in two recirculating AHAB systems (Aquatic Habitats, Apopka, FL, USA) under a 14:10 h light:dark cycle. Killifish used for behavioral testing were maintained at a starting density of 20 killifish per 10-1 tank, and killifish reared to 5 months had a starting density of 30 killifish per 10-l tank. Adult care and reproductive techniques are non-invasive and have been reviewed and approved by the Duke University Institutional Animal Care \& Use Committee.

\subsection{Sediment collection and deformity assessment}

The resistance to the acute toxicity and teratogenesis caused by Elizabeth River sediments, PAHs, PCB-126, and several pesticides has been well demonstrated and characterized in previous studies using the AWI site killifish (Meyer and Di Giulio, 2002, 2003; Meyer et al., 2002; Clark et al., 2010, 2013; Clark and Di Giulio, 2012). However, new sediments from the AWI site were collected for this study using a total PAH (TPAH) heat map from the United States Navy (2003), and due to the changing dynamics of the site, the extract was chemically analyzed for up-to-date characterization and new dose response exposures were performed. Embryos exposed to ERSE at $24 \mathrm{hpf}$ were scored for cardiac deformities at $144 \mathrm{hpf}$. The embryos were screened in a double blinded fashion using a semi-quantitative scale previously used and shown in detail (Matson et al., 2008; Clark et al., 2010). The scale is used to categorize cardiac structural alteration as normal (0), mild misalignment of cardiac chambers (1), and severe cardiac misalignment/tube heart (2). Embryos receiving a score of 0 had hearts with normal appearance including properly aligned and sized chambers, no visible pericardial edema, and unrestricted blood flow. Embryos assigned a score of 1 had slightly elongated hearts, with distinct misaligned chambers, and potentially visible pericardial edema. Hearts receiving a score of 2 had no identifiable chambers and extremely reduced or absence of blood flow. Only embryos receiving a score of 0 at $144 \mathrm{hpf}$ were used in subsequent larval and adult experiments addressing later life consequences.

\subsection{Larval mobility}

To quantify larval movement and the capacity to adapt to changing environmental stimuli, we adapted a behavioral test for assessing larval swimming activity, which also captures larval capacity to adapt to illumination conditions (Padilla et al., 2011; Ahmad et al., 2012; Padilla et al., 2012; Irons et al., 2013). At 4 days post hatch larvae were randomly transferred to a 48-well plate (1 larva per well) and allowed to acclimate in the dark for $1 \mathrm{~h}$ before being transferred to a DanioVision ${ }^{\mathrm{TM}}$ observation chamber (Noldus, Wageningen, The Netherlands). The same plate was used for all testing. Images of the DanioVision ${ }^{\mathrm{TM}}$ apparatus and other zebrafish behavioral assays can be found in Ahmad et al. (2012). Here, swimming distance was monitored for 50 min in alternating 10 min dark ("0\% illumination", $<1 \mathrm{~lx}$ ) and light ("100\% illumination", $5000 \mathrm{~lx}$ ) periods, starting with a $10 \mathrm{~min}$ habituation period in the dark. Larval motion was recorded at a sample rate of 30 times/s via a high speed infrared camera. Video data were then analyzed by computer tracking software, EthoVision XT® (Noldus, Wageningen, The Netherlands), to calculate total distance moved for each individual larvae over the course of the trial. Thirty larvae from each treatment within each population (KC and AW) were tested for mobility. ERSE dilutions for the larval mobility assay were determined based on the cardiac deformity assessment. Only embryos demonstrating no overt cardiac abnormalities were used in larval testing. KC killifish were exposed to Control, $0.1 \%, 1 \%$, and $2 \%$ dilutions of ERSE; whereas, AW killifish were exposed to Control, $0.1 \%, 1.0 \%, 2 \%, 3 \%$, and 5\% ERSE dilutions (note that the wider dilution range in AW killifish is because they demonstrated resistance to the cardiotoxic effects of ERSE exposure).

\subsection{Tap startle and habituation test}

The testing apparatus for this assay consisted of a flat white plastic $20.4 \mathrm{~cm} \times 38.1 \mathrm{~cm}$ surface with white $12.7 \mathrm{~cm} \times 15.2 \mathrm{~cm}$ plastic frontal and rear blocking barriers attached. Eight $5.1 \mathrm{~cm} \times 7.6 \mathrm{~cm}$ clear cylindrical arenas made of Plexiglas and arranged in 2 rows of 4 wells each (see Sledge et al. (2011)) and were attached to the flat plastic surface (Eddins et al., 2009; Sledge et al., 2011). Each arena contained $30 \mathrm{ml}$ of ASW. The apparatus rested between two $50.8 \mathrm{~cm}$ white opaque barriers, which faced each other and projected a bare white screen. Mechanical solenoids were positioned underneath each cylindrical arena. A Sony HD HandyCam was located approximately $71 \mathrm{~cm}$ above the apparatus. The solenoids were computer timed to deliver physical taps to the bottom of the cylindrical arenas. Killifish were tested at 3 months post hatch after being reared without further exposures in 10-L tanks in groups of 15. Eight killifish were blindly tested in each tap-test run. Killifish were removed from the holding tanks and each one was placed into a cylindrical arena on the tap apparatus. In total, 15 fish were tested per treatment, per population $(n=15)$. Killifish were allowed to acclimate in the arena for $5 \mathrm{~min}$ prior to testing. After the $5 \mathrm{~min}$ acclamation period, the tap test was started and solenoids tapped the testing arenas at $1 \mathrm{~min}$ intervals for 10 consecutive min. Distance traveled was recorded $5 \mathrm{~s}$ before the tap and $5 \mathrm{~s}$ after the tap (total testing time was 10 min) using EthoVision ${ }^{\mathrm{TM}}$ tracking software (Noldus, Wageningen, Netherlands).

\subsection{Novel tank dive test}

Killifish were tested at 3 months post hatch after being reared in 10L tanks in groups of 15 ( $\mathrm{n}=15$ fish per treatment/population). Two killifish were placed separately in two $1.5-1$ plastic tanks filled with $1350 \mathrm{ml}$ of ASW. The tanks were trapezoidal in shape and extended $22.9 \mathrm{~cm}$ along the bottom and $27.9 \mathrm{~cm}$ in length cross the top. The diagonal side of the tank was $15.9 \mathrm{~cm}$ in length and the opposing side was $15.2 \mathrm{~cm}$ long (Levin and Cerutti, 2008). Behavior was tracked in realtime using EthoVision tracking software (Noldus Information and Technology), which calculated distance from the tank floor and total 
distance traveled. Each trial was 5 min in duration and commenced immediately after a fish was placed in the tank. The video signal was transmitted through a Samsung camcorder that was positioned $88 \mathrm{~cm}$ away from the horizontal facing tanks.

\subsection{Statistical analysis}

Experiments assessing cardiac deformities were repeated three times with 10 vials per treatment, each containing 1 embryo per experiment ( $\mathrm{n}=10$ per experimental replicate, with three experimental reps for a total $n=30$ ). Statistical analyses for the cardiac deformity screening were performed using JMP 10.1.1 (SAS Institute Inc., Cary, NC, USA). These data were analyzed via one-way analysis of variance (ANOVA) followed by a Tukey-Kramer post hoc test. No differences between experimental replicates were observed for any test. Data are represented as mean \pm standard error of the mean (SEM). Values are considered significantly different at $\mathrm{p}<0.05$.

Dependent measures corresponding to each larval and adult assay are described above. When appropriate, log transformations were performed on raw data if variability increased proportionally with magnitude or if distributions were positively or negatively skewed. All statistical analyses were performed using Superanova/Statview (SAS; Cary, NC, USA) and all graphs were made using SigmaPlot (SYSTAT Software Inc., Richmond, CA, USA). The Type 1 error rate $(\alpha)$ was set at 0.05 for all omnibus tests and Dunnett's post hoc comparisons. A repeatedmeasures analysis of variance (RMANOVA) was performed for each dependent variable of interest. ERSA concentration served as betweensubject factors; tap number, session min, or condition served as within subject factors. When appropriate, e.g. where the adjustment to the degrees of freedom was less than 0.8 , Huyn-Feldt or Greenhouse-Geiser adjustments to degrees of freedom were used to account for lack of sphericity in the dataset. Data are reported in figures as means \pm SEM and significance is depicted graphically with an "*”.

\section{Results}

\subsection{Semi-quantitative cardiac abnormality dose response}

The data (Fig. 1) demonstrated the remarkable resistance of the AW killifish (resistant to 50\% ERSE dilution) to PAH-induced cardiac teratogenesis. Exposures also helped to inform our decisions for long-term rearing in KC killifish. These data indicate that consistent, overt cardiac abnormalities (scores $\geq 1$ ) appearing between dilutions of 1-3\% ERSE. Therefore, we selected $0.1 \%$ as our representative "low-level" ERSE exposure and $1.0 \%$ as our "high-level" ERSE exposure (TPAH $5.04 \mu \mathrm{g} / \mathrm{L}$ and $50.4 \mu \mathrm{g} / \mathrm{L}$ respectively). The AW killifish could developmentally tolerate up to $50.0 \%$ ERSE dilution (TPAH $8100 \mu \mathrm{g} / \mathrm{L}$ ) exposure before significant differences $(\mathrm{p}<0.05)$ in cardiac deformities were observed.

\subsection{Embryonic ERSE exposure causes increased later-life mortality}

Long-term mortality was assessed throughout rearing of the killifish used in this study (AHAB with $\mathrm{n}=30$ killifish per $10-1$ tank). Survival data (Table. 1) was taken at 1,2 , and 5 months post-hatch. The data showed steady decline in survival among AW killifish over the 5month period in all treatments. AW killifish experienced higher mortality relative to KC killifish by month 2 of sampling ( $p<0.05$ ); however, there were no significant differences in AW mortality with regard to ERSE dilution exposure. Unexposed KC killifish had low mortality over the 5-month rearing (less than 10\% mortality) and KC killfish treated with $0.1 \%$ ERSE dilution did not significantly differ in survivorship. However, KC killifish exposed as embryos to high-level (1.0\% ERSE) demonstrated significant mortality at both 2 and 5 months ph $(\mathrm{p}<0.05)$ relative to untreated controls. At 5 months, 1.0\% ERSE exposed KC survival paralleled AW survivorship.
Table 1

Five-month survival of $F$. heteroclitus exposed to dilutions of Elizabeth River sediment extract. The survival table represents $n=90$ fish per treatment group (total fish from 3 experimental replicates of $n=30$ each). Data show mean surviving fish at time sampled \pm standard error out of 30 individuals. Mortality that is statistically different from KC control mortality at time sampled ( $\mathrm{p} \leq 0.05$ ) is bolded and marked with an asterisk.

\begin{tabular}{llll}
\hline Mortality & 1 Month & 2 Months & 5 Months \\
\hline KC C & $28.7 \pm 0.3$ & $27.7 \pm 0.3$ & $26.7 \pm 0.3$ \\
KC 0.1\% & $27.7 \pm 0.3$ & $27.3 \pm 0.3$ & $24.7 \pm 1.3$ \\
KC $1.0 \%$ & $26.3 \pm 0.6$ & $24.0 \pm 0.6^{*}$ & $21.0 \pm 0.6^{*}$ \\
AW C & $26.3 \pm 0.3$ & $23.3 \pm 0.6^{*}$ & $21.7 \pm 0.3^{*}$ \\
AW 0.1\% & $26.7 \pm 0.3$ & $22.7 \pm 0.3^{*}$ & $21.3 \pm 0.3^{*}$ \\
AW $1.0 \%$ & $27.0 \pm 0.6$ & $23.0 \pm 0.6^{*}$ & $22.0 \pm 0.6^{*}$ \\
\hline
\end{tabular}

\subsection{ERSE exposure alters larval mobility}

Control killifish from both populations exhibited similar light/dark locomotor activity (Fig. 2) with high activity levels in 10-min dark periods and less activity in 10-min light phases. The data indicated a complex, nonmonotonic response in KC killifish mobility (Fig. 3) following ERSE exposure. The $0.1 \%$ dilution of ERSE caused statistically significant reductions in swimming activity (hypoactivity) during the high activity dark periods $(\mathrm{p}<0.05)$. However, the $1.0 \%$ ERSE dilution exposure caused hyperactivity in the KC larvae. The $2 \%$ ERSE exposure did not cause a statistically significant difference in mobility; however, this treatment had significantly higher larval mortality from hatch to day 4 ph (only $n=23$ survived to be screened).

Mobility in the AW killifish remained consistent across ERSE treatments (Fig. 4). No differences were observed in larval mobility during light or dark cycles. In addition, ERSE dilutions were increased beyond concentrations that would cause cardiac abnormalities in KC killifish. These data suggest that not only are AW killifish resistant to acute PAH induced cardiac abnormalities, but they are also resistant to the larval behavioral impacts of ERSE exposures.

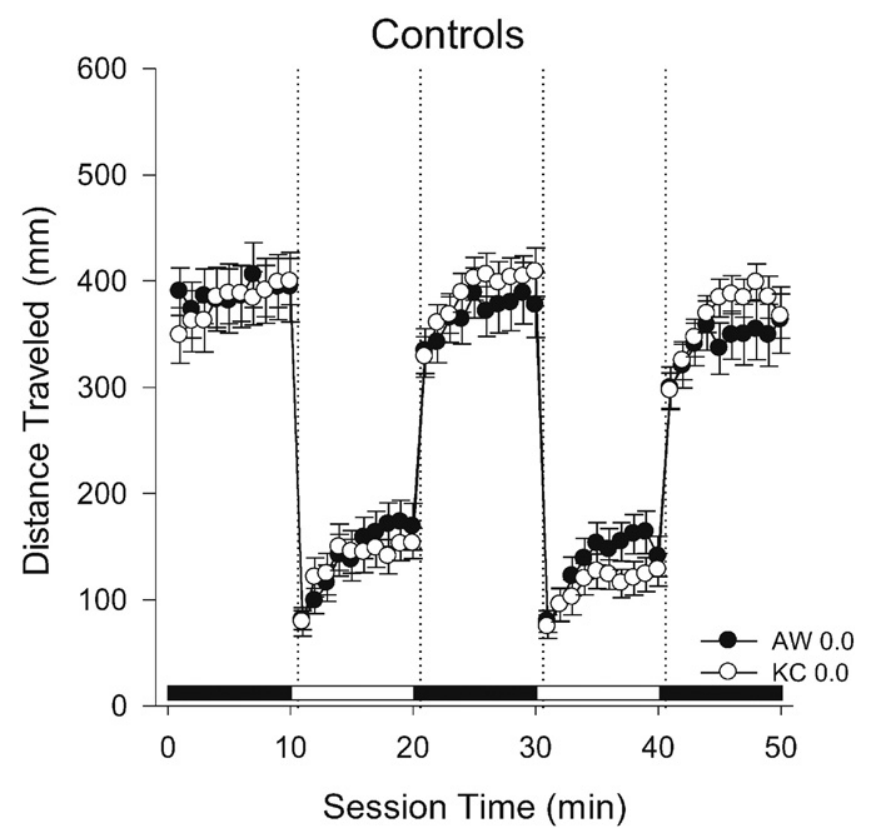

Fig. 2. Control larval mobility at 4 days post-hatch in KC and AW killifish. The line plot shows swimming activity of $\mathrm{n}=30$ larvae per population. White circles represent Kings Creek killifish and black circles represent Atlantic Wood killifish. Alternating black and white bars on the x-axis signify 10-min intervals of dark and light exposure in the Daniovision ${ }^{\circledR}$ chamber. Activity levels did not vary between populations. 


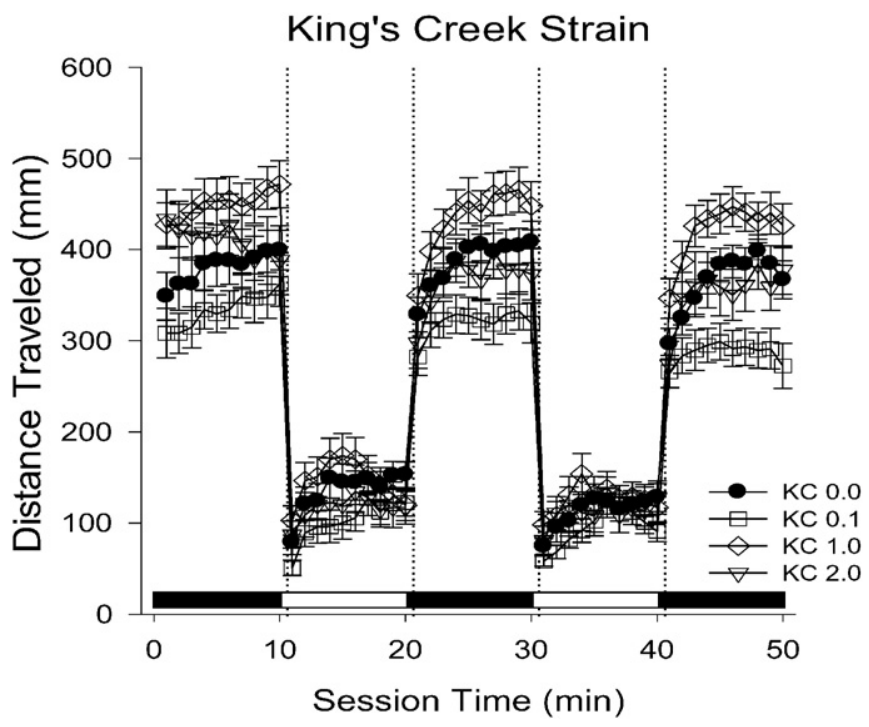

Fig. 3. Larval mobility at 4 days post-hatch $K C$ killifish exposed as embryos at $24 \mathrm{~h}$ post fertilization to dilutions of ERSE. The line plot shows swimming activity of $\mathrm{n}=30$ larvae per treatment group. Treatments correspond to shapes and represent KC killifish exposed as embryos to diluted ERSE. Low exposure 0.1\% ERSE dilution caused significant decreased in swimming activity ( $\mathrm{p} \leq 0.05$ ) during dark-cycle intervals. However, the 1.0\% ERSE exposure caused significant increases in activity.

\subsection{ERSE exposure causes hyperactivity}

After 3-months of lab rearing, killifish were assessed for habituation in a tap-stimulus assay (Fig. 5). There were no significant differences between unexposed KC and AW killifish. However, high level ERSE exposure caused significant increases in mean distance traveled in $\mathrm{KC}$ killifish (KC $1 \%, \mathrm{p} \leq 0.5)$. AW killifish did not demonstrate any differences in activity across ERSE treatments.

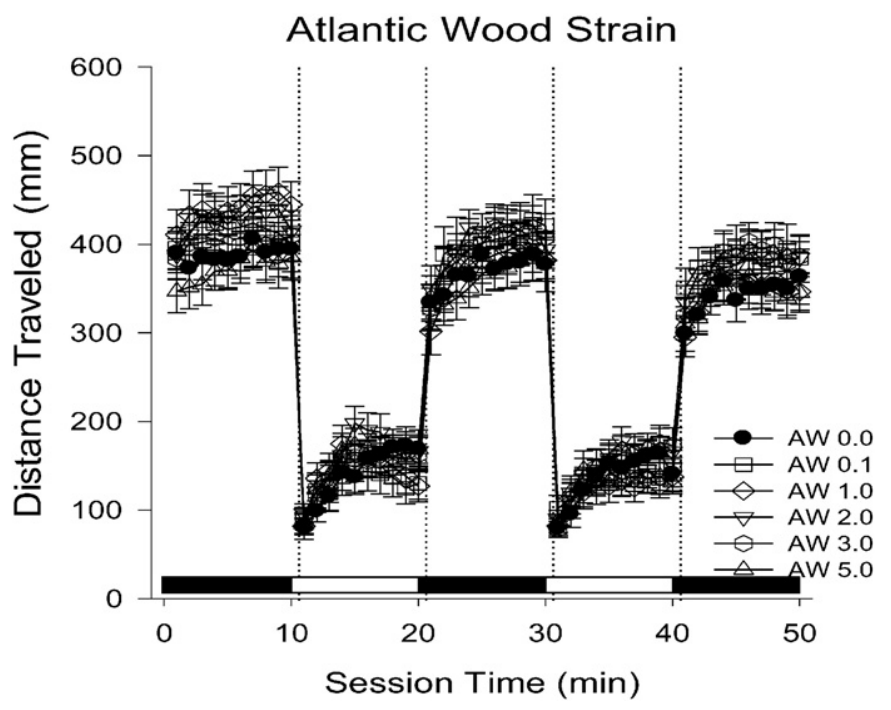

Fig. 4. Larval mobility at 4 days post-hatch AW killifish exposed as embryos at $24 \mathrm{~h}$ post fertilization to dilutions of ERSE. The line plot shows swimming activity (mean distance traveled in $\mathrm{cm}$ ) in $\mathrm{n}=30$ larvae per treatment group. Treatments correspond to shapes and represent AW killifish exposed as embryos to diluted ERSE. AW killifish showed no differences in swimming activity with respect to treatment. The ERSE dilutions used for AW killifish exceed dilutions known to cause stringy heart in KC killifish. There were no significant increases in embryonic mortality or reductions in hatching rate.

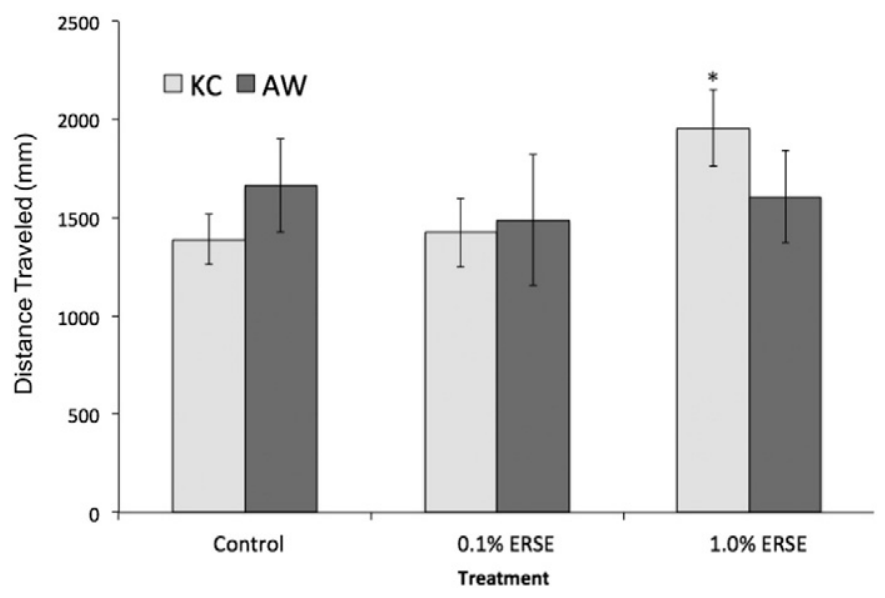

Fig. 5. Mean distance moved in Tap Startle and Habituation Test. The graph shows mean distance traveled (in $\mathrm{cm}$ ) in the tap-test by $\mathrm{n}=30-45$, 3-month old killifish. KC killifish are shown as lighter bars and AW killifish are shown as darker gray bars. The 1.0\% ERSE treated KC killifish showed significant increases in mean distance traveled compared to controls $(\mathrm{p} \leq 0.05)$.

\subsection{ERSE exposure causes increased anxiety}

Following the habituation assay, killifish also completed the dive test. KC killifish demonstrated no significant difference in mean distance traveled (Fig. 6), and showed irregular exploration patterns (i.e., activity did not necessarily increase over the 5 -min testing period). AW killifish showed significant increases in mean travel distance in the highest treatment group (AW 1.0\% p < 0.05), but their travel distance declined over the 5-min testing period. KC killifish exposed to the highest ERSE dilution stayed significantly closer to the bottom of the chamber (Fig. 7) throughout testing $(\mathrm{p}<0.05)$. Conversely, AW killifish showed no significant differences in travel distance from the bottom of the novel chamber. These data suggest ERSE exposure increased time spent on the bottom in KC killifish, which is indicative of increased anxiety/predator avoidance behavior.

\section{Discussion}

Our study demonstrated that developmental exposure to a complex PAH mixture significantly altered behavior and locomotor activity in killifish, and that these behavioral changes persisted into adulthood. This study also suggested that while the PAH-adapted AW killifish have long-term rearing mortality costs in clean water, this population was not significantly impacted behaviorally by embryonic ERSE exposure. However, the specific mechanisms leading to these observed behavioral outcomes remain unclear and warrant investigation in future studies.

Evidence of resistance of Elizabeth River killifish to effects of PAH was first published by Van Veld and Westbrook (1995). In this study, cytochrome P4501A (CYP1A) response was compared in adult fish collected from the AW site and two reference sites (Wilson Creek and King's Creek, both north of the mouth of the York River, in Gloucester County, VA). CYP1A is a major enzyme involved in Phase I, oxidative biotransformation of xenobiotics. Data demonstrated that fish from the AW site exhibited a remarkable resistance to induction of CYP1A by PAH. The resistance of AW killifish to PAHs and to PCB-126 was further investigated in the Di Giulio lab (Meyer et al., 2002; Meyer and Di Giulio, 2002, 2003). These studies further determined both pattern and heritability of recalcitrant CYP1A response previously observed in adult Elizabeth River killifish by Van Veld and Westbrook (1995). In addition to refractory induction of CYP1A, other studies have demonstrated that the AW killifish population demonstrates upregulated phase II and III metabolizing enzymes (Vanveld et al., 1991; Armknecht et al., 1998; Gaworecki et al., 2004). It is thought that these enzymes play a 

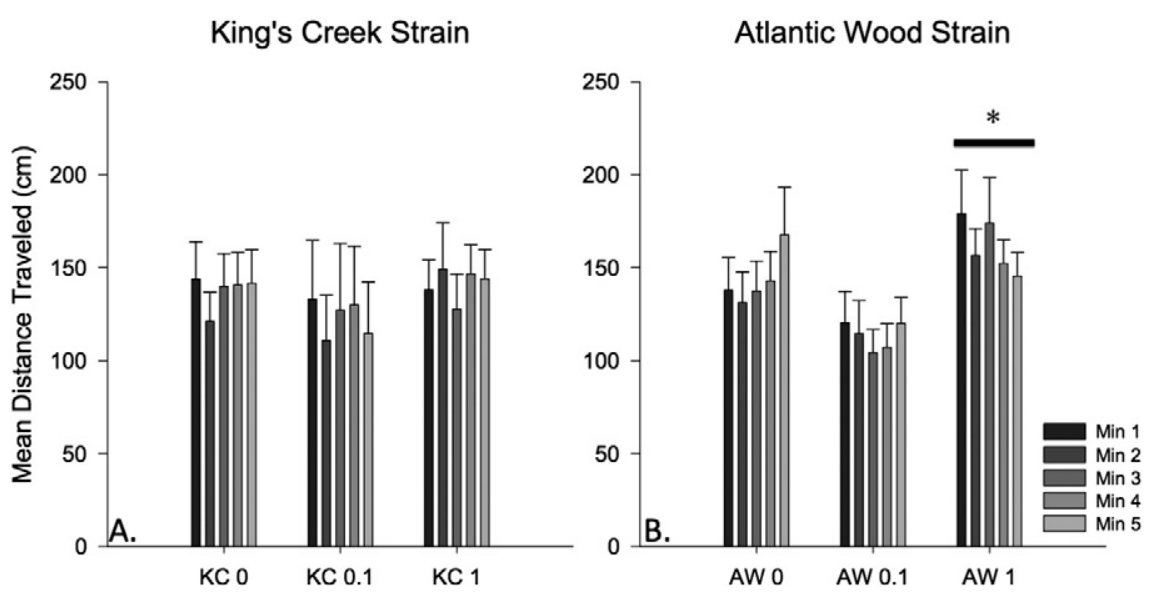

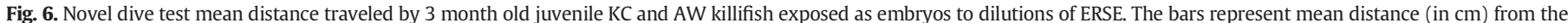

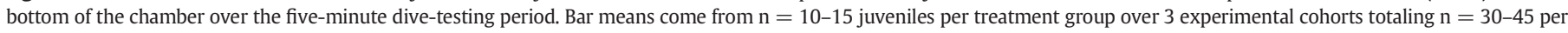
bar. AW killifish exposed to $1.0 \%$ ERSE dilution travel significantly more than untreated AW killifish ( $\mathrm{p} \leq 0.05$ ).

detoxifying role in chemical exposures to this population of killifish. Although studies have investigated mechanisms underlying the PAHadaptation in the AW population, this is the first study to investigate and compare behavior within this population in conjunction with $\mathrm{PAH}$ exposure.

Some studies have highlighted behavioral and performance differences in adult fish following exposure to individual and PAH mixtures. Carvalho et al. (2008) demonstrated that waterborne exposure of dorado (Salminus brasiliensis) larvae to phenanthrene produced reduction of larvae ability to capture prey, and that the deficits were most pronounced when exposures occurred immediately following hatching. Other studies have found reductions in long-term growth and reproduction following early life exposure to PAH mixtures (Carls et al., 1999; Heintz et al., 1999; Cachot et al., 2007). The most recent research suggests that subteratogenic embryonic exposure to PAHs can target the heart causing subtle alterations and damage, and that this cardiac damage can lead to altered later life performance.

Hicken et al. (2011) demonstrated that transient embryonic exposure of zebrafish to petroleum caused sublethal cardiotoxicity. Nearly a year after embryonic oil exposure, adult zebrafish in the study showed subtle changes in heart shape and a significant reduction in swimming performance, indicative of reduced cardiac output. Marit and Weber (2012) showed that zebrafish exposed to sublethal concentrations of TCDD as larvae had significant decreases in swimming performance and dorsal aorta diameter, despite having equal survivability with concomitant control zebrafish. These physiological impacts on cardiovascular performance at later life stages provide a potential mechanism linking reduced individual survival to population-level ecosystem responses of fish species to chronic, low-level hydrocarbon pollution (Hicken et al., 2011; Vignet et al., 2014a, 2014b).

Another working hypothesis is that subteratogenic embryonic PAH exposure alters neurotransmitter signals resulting in persistent behavioral alterations. This hypothesis has been supported by a study in rainbow trout (Oncorhynchus mykiss) using BaP and $\beta$-naphthoflavone, two prototypic AHR agonists (Gesto et al., 2008). Disruption to the dopaminergic and serotonergic systems in the brain caused increased neurotransmitter turnover. There is also growing epidemiological evidence that PAHs are developmental toxicants in humans (Perera et al., 1998, 2005, 2011, 2012, 2014a, 2014b). Perera et al. (2011) followed over 200 New York City children from in utero to 7-8 years of age after measuring PAH-DNA adducts and other bulky aromatic adducts in the umbilical cords of their mothers. Children of mothers with higher cord adducts were associated with poorer behavioral outcomes as measured by the age appropriate Child Bahavior Checklist (CBCL; Perera et al., 2011). This behavioral screening technique has been used and is sensitive to diverse prenatal environmental exposures (Axtell et al. 2000; Rauh et al. 2006). These human epidemiological studies have been further corroborated by rodent studies of benzo(a)pyrene (BaP)
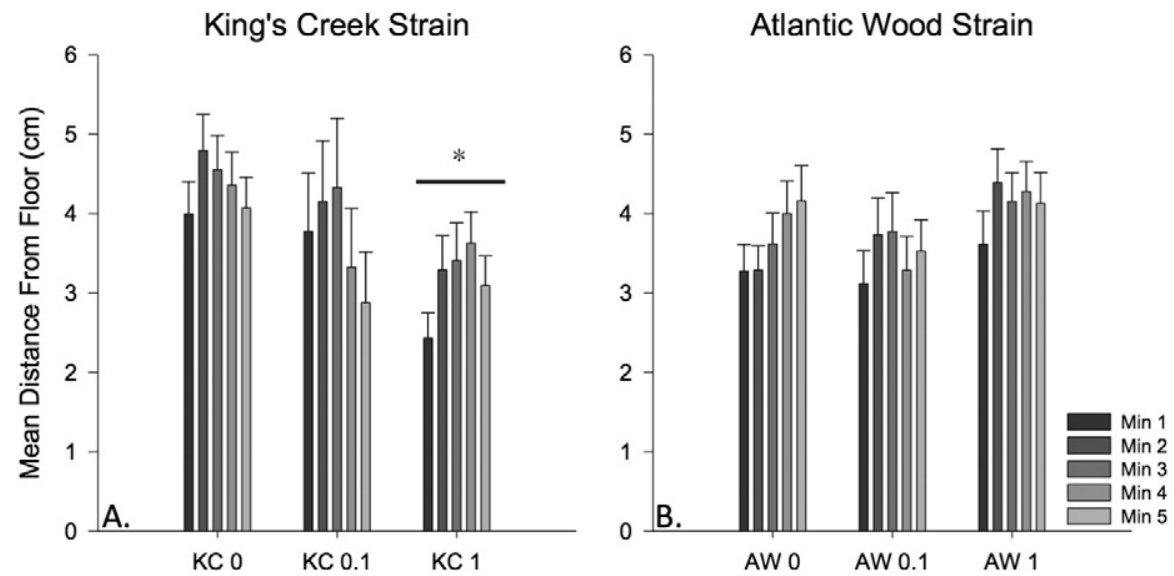

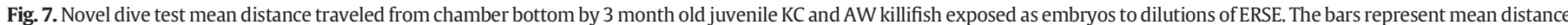

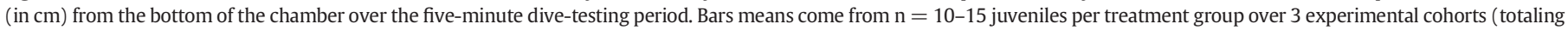

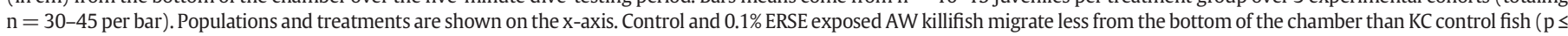
$0.05)$. 
(Chen et al., 2012). Sprague-Dawley rats exposed postnatally to benzo(a)pyrene (BaP) showed significant neurobehavioral impairments that persisted into adolescence and adulthood. Our study adds to growing environmental and human health based literature suggesting that early life exposure to PAHs can have long-term performance and behavioral consequences. While these assays help to reveal later life consequences of early life PAH exposure, they lack the ability to explore the cardiac and/or neural mechanisms of action.

The larval mobility assay used in this study is a common behavioral test for assessing larval swimming activity, and can provide meaningful information about the capacity of larvae to adapt to changing environmental stimuli. Previous studies have primarily used zebrafish as a model for chemical exposure scenarios (Ahmad et al., 2012; Padilla et al., 2011). Our study demonstrated that the adapted AW population mimics the larval locomotor activity of the KC population in both light and dark cycles under control conditions. This suggests that $\mathrm{KC}$ and AW larvae are initially of similar health when reared in clean water. This is significant given the long term rearing data demonstrating greater mortality levels in the AW killifish population.

Field observation suggests that parental AW killifish appear to be healthy and thriving at the AWI Superfund site (Meyer and Di Giuliuo, 2003). However, parental AW killifish reared in the laboratory develop skin lesions over time and experience greater levels of mortality relative to KC killifish. This study demonstrates that lab reared AW offspring experience increased mortality relative to the naïve $\mathrm{KC}$ killifish offspring. In addition, $\mathrm{KC}$ killifish exposed to the high dilution (1.0\%) ERSE treatment showed increased levels of mortality. Because of the evolutionary relationship between the AW killifish and the sediment at the AWI site, it is reasonable to suggest that the sediment could be protective of the AW killifish by regulating bacteria and parasite populations, and potentially influencing gut flora. These findings suggest that there are physiological and survivorship costs associated with possessing the adapted phenotype (AW killifish) and that early embryonic exposure to ERSE/ complex PAH mixtures is capable of causing behavioral alterations in KC killifish. However, ERSE exposure has little behavioral or survival impact on AW killifish. These health costs in the AW population when reared in clean water should be explored in more detail and future studies should investigate the differences between these populations by comparing their relative health in clean water rearing conditions and AWI sediment conditions.

ERSE exposure caused both hyperactivity and hypoactivity in KC larval mobility depending on exposure concentrations $(0.1 \%$ dilution caused decreased swimming activity whereas, 1.0\% ERSE caused hyperactivity). The subteratogenic exposures used in this study and the nonmonotonic dose response provide slightly more support for a neurobehavioral compromising effect of PAH exposure. If the heart is the only target at low level PAH exposure, one might expect a consistent decline in activity with increasing exposure. Given that the $1.0 \%$ exposure increased activity in both larvae and long term reared KC killifish, it could be indicative of a more neurotoxic effect. However, later life mortality in the 1.0\% ERSE exposed killifish strengthens the case of a cardiotoxic mechanism. In either case, more studies should be done to investigate specific mechanisms of action in larval and adult stages following embryonic exposure.

The activity pattern in PAH adapted AW killifish is not significantly altered by ERSE dilution exposure, even at concentrations that cause overt cardiac abnormalities in KC killifish. This suggests that AW killifish are not only resistant to the developmental cardiac effects of PAH exposure (Meyer et al., 2002, 2003; Meyer and Di Giuliuo, 2003; Clark et al., 2010; Clark and Di Giulio, 2012), but that they are also tolerant of the behavioral and locomotor effects of low-level exposure. Given our knowledge of the AW killifish resistance to the cardiotoxic effects of $\mathrm{PAH}$ exposure, and their locomotor and behavioral resistance observed in this study, it is reasonable to assert that subtle cardiotoxic and circulatory effects may temporarily precede the neurologic effects in the $\mathrm{KC}$ killifish population. However, it is also possible that the AW killifish population is avoiding both cardiac and neurological toxicity through multiple mechanisms of resistance and differential metabolism. Therefore, this study highlights the need for better temporal characterization of defects following low-level PAH exposures.

Long-term reared $\mathrm{KC}$ killifish showed hyperactivity in the taptest and less migration from the bottom of the chamber in the novel dive task assay (at 3 months post hatching) following high ERSE exposure. Conversely, AW killifish activity levels demonstrated no significant changes following ERSE exposure. Additionally, differences were observed in long-term rearing mortality between populations and treatments. The hyperactivity observed in the larval assay appears to persist into juvenile stages of development, as indicated by the tap and dive test assays. KC killifish demonstrated hyperactivity in the tap-test and spent more time on the bottom of the novel-tank dive test. The low level $0.1 \%$ dilution, while causing decreases in larval swimming activity, does not appear to have persistent behavioral effects over time in the KC population. AW killifish exposed to high level ERSE dilution 1.0\% demonstrate the most distance traveled in the dive assay. This suggests that AW killifish do not have long-term locomotor/behavioral impacts following ERSE exposure. However, it is also important to note evident differences in AW survivorship over time.

This behavioral study of killifish exposed as embryos to pore water from the Elizabeth River Superfund site creates a framework for future evaluations of environmental contamination scenarios. Early life subteratogenic exposure to PAHs derived from creosote contamination caused increased mortality over time and showed long-term behavioral consequences that may impact environmental survivorship and performance in killifish. The observed alterations in larval mobility and adult behavior raise interesting questions about the environmental impacts and costs associated with ERSE and PAH mixture exposure and the adapted phenotype. Future studies should molecularly characterize the temporal order of cardiac and neurological defects following low-level PAH mixture exposure. Studies should also consider investigating predator-prey interactions to better determine the realistic consequences of locomotor and behavior alterations caused by PAH exposure. In addition, our findings corroborate and may be able to inform human health studies investigating early life exposures to PAHs.

\section{Transparency document}

The Transparency document associated with this article can be found, in the online version.

\section{References}

Ahmad, F., et al., 2012. Zebrafish embryos and larvae in behavioural assays. Behaviour 149 (10-12), 1241-1281.

Antkiewicz, D.S., et al., 2005. Heart malformation is an early response to TCDD in embryonic zebrafish. Toxicol. Sci. 84 (2), 368-377.

Armknecht, S.L., et al., 1998. An elevated glutathione S-transferase in creosote-resistant mummichog (Fundulus heteroclitus). Aquat. Toxicol. 41 (1-2), 1-16.

Axtell, C.D., et al., 2000. Association between methylmercury exposure from fish consumption and child development at five and a half years of age in the Seychelles Child Development Study: An evaluation of nonlinear relationships. Environ. Res. 84 (2), 71-80.

Bailey, J., et al., 2013. Zebrafish model systems for developmental neurobehavioral toxicology. Birth Defects Res. C Embryo Today 99 (1), 14-23.

Barron, M.G., et al., 2004. Evaluation of fish early life-stage toxicity models of chronic embryonic exposures to complex polycyclic aromatic hydrocarbon mixtures. Toxicol. Sci. 78 (1), 60-67.

Baumard, P., et al., 1998. Concentrations of PAHs (polycyclic aromatic hydrocarbons) in various marine organisms in relation to those in sediments and to trophic level. Mar. Pollut. Bull. 36 (12), 951-960.

Benlahcen, KT. et al., 1997. Distribution and sources of polycyclic aromatic hydrocarbons in some Mediterranean coastal sediments. Mar. Pollut. Bull. 34 (5), 298-305.

Burnett, K.G., et al., 2007. Fundulus as the premier teleost model in environmental biology: opportunities for new insights using genomics. Comp. Biochem. Physiol. D: Genomics Proteomics 2 (4), 257-286. 
Cachot, J., et al., 2006. Evidence of genotoxicity related to high PAH content of sediments in the upper part of the Seine estuary (Normandy, France). Aquat. Toxicol. 79 (3), 257-267.

Cachot, J., et al., 2007. Characterization of toxic effects of sediment-associated organic pollutants using the lambda transgenic medaka. Environ. Sci. Technol. 41 (22), 7830-7836.

Cantrell, S.M., et al., 1996. Embryotoxicity of 2,3,7,8-tetrachlorodibenzo-p-dioxin (TCDD): the embryonic vasculature is a physiological target for TCDD-induced DNA damage and apoptotic cell death in medaka (orizias latipes). Toxicol. Appl. Pharmacol. 141 (1), 23-34.

Carls, M.G., et al., 1999. Sensitivity of fish embryos to weathered crude oil: part I. Low-level exposure during incubation causes malformations, genetic damage, and mortality in larval Pacific herring (Clupea pallasi). Environ. Toxicol. Chem. 18 (3), 481-493.

Carls, M.G., et al., 2008. Fish embryos are damaged by dissolved PAHs, not oil particles. Aquat. Toxicol. 88 (2), 121-127.

Carney, S.A., et al., 2006. Understanding dioxin developmental toxicity using the zebrafish model. Birth Defects Res. A Clin. Mol. Teratol. 76 (1), 7-18.

Carvalho, P.S.M., et al., 2008. Effects of naphthalene and phenanthrene on visual and prey capture endpoints during early stages of the dourado Salminus Brasiliensis. Mar. Environ. Res. 66 (1), 205-207.

Chen, C.Z., et al., 2012. Early postnatal benzo(a)pyrene exposure in Sprague-Dawley rats causes persistent neurobehavioral impairments that emerge postnatally and continue into adolescence and adulthood. Toxicol. Sci. 125 (1), 248-261.

Clark, B.W., Di Giulio, R.T., 2012. Fundulus heteroclitus adapted to PAHs are crossresistant to multiple insecticides. Ecotoxicology 21 (2), 465-474.

Clark, B.W., et al., 2010. AHR2 mediates cardiac teratogenesis of polycyclic aromatic hydrocarbons and PCB-126 in Atlantic killifish (Fundulus heteroclitus). Aquat. Toxicol. 99 (2), 232-240.

Clark, B.W., et al., 2013. Compound- and mixture-specific differences in resistance to polycyclic aromatic hydrocarbons and PCB-126 among Fundulus heteroclitus subpopulations throughout the Elizabeth river estuary (Virginia, USA). Environ. Sci. Technol. 47 (18), 10556-10566.

Djomo, J.E., et al., 1996. Uptake and depuration of polycyclic aromatic hydrocarbons from sediment by the zebrafish (Brachydanio rerio). Environ. Toxicol. Chem. 15 (7), 1177-1181.

Eddins, D., et al., 2009. Nicotine effects on learning in zebrafish: the role of dopaminergic systems. Psychopharmacology 202 (1-3), 103-109.

Fang, M.L., et al., 2014. Effect-directed analysis of Elizabeth river porewater: developmental toxicity in zebrafish (Danio rerio). Environ. Toxicol. Chem. 33 (12), 2767-2774.

Foan, L., et al., 2010. Reconstructing historical trends of polycyclic aromatic hydrocarbon deposition in a remote area of Spain using herbarium moss material. Atmos. Environ. 44 (26), 3207-3214

Gaworecki, K.M., et al., 2004. Induction of phenol-type sulfotransferase and glucuronosyltransferase in channel catfish and mummichog. Mar. Environ. Res. 58 (2-5), 525-528.

Gesto, M., et al., 2008. Acute and prolonged stress responses of brain monoaminergic activity and plasma cortisol levels in rainbow trout are modified by PAHs (naphthalene, beta-naphthoflavone and benzo(a)pyrene) treatment. Aquat. Toxicol. 86 (3), 341-351.

Heintz, R.A., et al., 1999. Sensitivity of fish embryos to weathered crude oil: part II. Increased mortality of pink salmon (Oncorhynchus gorbuscha) embryos incubating downstream from weathered Exxon Valdez crude oil. Environ. Toxicol. Chem. 18 (3), 494-503.

Helder, T., 1981. Effects of 2,3,7,8-tetrachlorodibenzo-para-dioxin (TCDD) on early life stages of rainbow-trout (Salmo-gairdneri, Richardson). Toxicology 19 (2), 101-112.

Henry, T.R., et al., 1997. Early life stage toxicity of 2,3,7,8-tetrachlorodibenzo-p-dioxin in zebrafish (Danio rerio). Toxicol. Appl. Pharmacol. 142 (1), 56-68.

Hicken, C.E., et al., 2011. Sublethal exposure to crude oil during embryonic development alters cardiac morphology and reduces aerobic capacity in adult fish. Proc. Natl. Acad. Sci. U. S. A. 108 (17), 7086-7090.

Hornung, M.W., et al., 1996. Toxic equivalency factors of polybrominated dibenzo-pdioxin, dibenzofuran, biphenyl, and polyhalogenated diphenyl ether congeners based on rainbow trout early life stage mortality. Toxicol. Appl. Pharmacol. 140 (2), 227-234.

Hylland, K., 2006. Polycyclic aromatic hydrocarbon (PAH) ecotoxicology in marine ecosystems. J. Toxic. Environ. Health A 69 (1-2), 109-123.

Incardona, J.P., et al., 2006. Developmental toxicity of 4-ring polycyclic aromatic hydrocarbons in zebrafish is differentially dependent on AH receptor isoforms and hepatic cytochrome P4501A metabolism. Toxicol. Appl. Pharmacol. 217 (3), 308-321.

Incardona, J.P., et al., 2009. Cardiac arrhythmia is the primary response of embryonic Pacific Herring (Clupea pallasi) exposed to crude oil during weathering. Environ. Sci. Technol. 43 (1), 201-207.

Incardona, J.P., et al., 2011. Cardiac toxicity of 5-ring polycyclic aromatic hydrocarbons is differentially dependent on the aryl hydrocarbon receptor 2 isoform during zebrafish development. Toxicol. Appl. Pharmacol. 257 (2), 242-249.

Irons, T.D., et al., 2013. Acute administration of dopaminergic drugs has differential effects on locomotion in larval zebrafish. Pharmacol. Biochem. Behav. 103 (4), 792-813.

Kneib, R.T., 1986. The role of Fundulus-heteroclitus in salt-marsh trophic dynamics. Am. Zool. 26 (1), 259-269.

Levin, E.D., Cerutti, D.T., 2008. Behavioral neuroscience of zebrafish. In: Buccafusco, J.J. (Ed.), Methods of Behavior Analysis in Neuroscience, 2nd edition New York, CRC Press, pp. 293-310.
Lotrich, V.A., 1975. Summer home range and movements of Fundulus-heteroclitus (Pisces-Cyprinodontidae) in a tidal creek. Ecology 56 (1), 191-198.

Marit, J.S., Weber, L.P., 2012. Persistent effects on adult swim performance and energetics in zebrafish developmentally exposed to 2,3,7,8-tetrachlorodibenzo-p-dioxin. Aquat. Toxicol. 106, 131-139.

Matson, C.W., et al., 2008. Development of the morpholino gene knockdown technique in Fundulus heteroclitus: a tool for studying molecular mechanisms in an established environmental model. Aquat. Toxicol. 87 (4), 289-295.

McElroy, A.E., et al., 2006. Uptake, metabolism, mutant frequencies and mutational spectra in lambda transgenic medaka embryos exposed to benzo[alpha]pyrene dosed sediments. Mar. Environ. Res. 62, S273-S277.

Meyer, J., Di Giulio, R., 2002. Patterns of heritability of decreased EROD activity and resistance to PCB 126-induced teratogenesis in laboratory-reared offspring of killifish (Fundulus heteroclitus) from a creosote-contaminated site in the Elizabeth River VA, USA. Mar. Environ. Res. 54 (3-5), 621-626.

Meyer, J.N., Di Giuliuo, R.T., 2003. Heritable adaptation and fitness costs in killifish (Fundulus beteroclitus) inhabiting a polluted estuary. Ecol. Appl. 13 (2), 490-503.

Meyer, J.N., et al., 2002. Cytochrome P4501A (CYP1A) in killifish (Fundulus heteroclitus): heritability of altered expression and relationship to survival in contaminated sediments. Toxicol. Sci. 68 (1), 69-81.

Meyer, J.N., et al., 2003. Antioxidant defenses in killifish (Fundulus heteroclitus) exposed to contaminated sediments and model prooxidants: short-term and heritable responses. Aquat. Toxicol. 65 (4), 377-395.

Moles, A., Rice, S.D., 1983. Effects of crude-oil and naphthalene on growth, caloric content, and fat-content of pink salmon juveniles in seawater. Trans. Am. Fish. Soc. 112 (2), 205-211.

Mulvey, M., et al., 2002. Genetic structure of Fundulus heteroclitus from PAHcontaminated and neighboring sites in the Elizabeth and York rivers. Aquat. Toxicol. 61 (3-4), 195-209.

Ownby, D.R., et al., 2002. Fish (Fundulus heteroclitus) populations with different exposure histories differ in tolerance of creosote-contaminated sediments. Environ. Toxicol. Chem. 21 (9), 1897-1902.

Padilla, S., et al., 2011. Assessing locomotor activity in larval zebrafish: influence of extrinsic and intrinsic variables. Neurotoxicol. Teratol. 33 (6), 624-630.

Padilla, S., et al., 2012. Zebrafish developmental screening of the ToxCast phase I chemical library. Reprod. Toxicol. 33 (2), 174-187.

Perera, F.P., Chang, H.W., et al., 2014b. Early-life exposure to polycyclic aromatic hydrocarbons and ADHD behavior problems. PLoS One 9 (11).

Perera, F.P., et al., 1998. Recent developments in molecular epidemiology - study of the effects of environmental polycyclic aromatic hydrocarbons on birth outcomes in Poland. Am. J. Epidemiol. 147 (3), 309-314.

Perera, F., et al., 2005. DNA damage from polycyclic aromatic hydrocarbons measured by benzo[a]pyrene-DNA adducts in mothers and newborns from northern Manhattan, the World Trade Center area, Poland, and China. Cancer Epidemiol. Biomark. Prev. 14 (3), 709-714.

Perera, F.P., et al., 2011. Polycyclic aromatic hydrocarbons-aromatic DNA adducts in cord blood and behavior scores in New York city children. Environ. Health Perspect. 119 (8), 1176-1181.

Perera, F.P., et al., 2012. Prenatal polycyclic aromatic hydrocarbon (PAH) exposure and child behavior at age 6-7 years. Environ. Health Perspect. 120 (6), 921-926.

Perera, F., et al., 2014a. Prenatal exposure to airborne polycyclic aromatic hydrocarbons and IQ: estimated benefit of pollution reduction. J. Public Health Policy 35 (3) 327-336.

Rauh, V.A., et al., 2006. Impact of prenatal chlorpyrifos exposure on neurodevelopment in the first 3 years of life among inner-city children. Pediatrics 118 (6), E1845-E1859.

Shen, H.Z., et al., 2013. Global atmospheric emissions of polycyclic aromatic hydrocarbons from 1960 to 2008 and future predictions. Environ. Sci. Technol. 47 (12), 6415-6424

Skinner, M.A., et al., 2005. Site fidelity of mummichogs (Fundulus heteroclitus) in an Atlantic Canadian estuary. Water Qual. Res. J. Can. 40 (3), 288-298.

Sledge, D., et al., 2011. Critical duration of exposure for developmental chlorpyrifosinduced neurobehavioral toxicity. Neurotoxicol. Teratol. 33 (6), 742-751.

Spitsbergen, J.M., et al., 1991. Pathological alterations in early life stages of lake trout Salvelinus-namaycush, exposed to 2,3,7,8-tetrachlorodibenzo-para-dioxin as fertilized-eggs. Aquat. Toxicol. 19 (1), 41-71.

Teo, S.L.H., Able, K.W., 2003. Growth and production of the mummichog (Fundulus heteroclitus) in a restored salt marsh. Estuaries 26 (1), 51-63.

Van Metre, P.C., Mahler, B.J., 2005. Trends in hydrophobic organic contaminants in urban and reference lake sediments across the United States, 1970-2001. Environ. Sci. Technol. 39 (15), 5567-5574.

Van Metre, P.C., et al., 2000. Urban sprawl leaves its PAH signature. Environ. Sci. Technol. 34 (19), 4064-4070.

Van Veld, P.A., Westbrook, D.J., 1995. Evidence for depression of cytochrome P4501A in a population of chemically resistant mummichog (Fundulus heteroclitus). Environ. Sci. 3, 221-234.

Vanveld, P.A., et al., 1991. Glutathione-S-transferase in intestine, liver and hepatic-lesions of mummichog (Fundulus heteroclitus) from a creosote-contaminated environment. Fish Physiol. Biochem. 9 (4), 369-376.

Vignet, C., et al., 2014a. Long-term disruption of growth, reproduction, and behavior after embryonic exposure of zebrafish to PAH-spiked sediment. Environ. Sci. Pollut. Res. 21 (24), 13877-13887.

Vignet, C., et al., 2014b. Chronic dietary exposure to pyrolytic and petrogenic mixtures of PAHs causes physiological disruption in zebrafish-part II: behavior. Environ. Sci. Pollut. Res. 21 (24), 13818-13832.

Walker, M.K., Peterson, R.E., 1991. Potencies of polychlorinated dibenzo-para-dioxin, dibenzofuran, and biphenyl congeners, relative to 2,3,7,8-tetrachlorodibenzo-para- 
dioxin, for producing early life stage mortality in rainbow-trout (Oncorhynchusmykiss). Aquat. Toxicol. 21 (3-4), 219-238.

Walker, M.K., et al., 1991. 2,3,7,8-tetrachlorodibenzo-para-dioxin (tcdd) toxicity during early life stage development of lake trout (Salvelinus-namaycush). Can. J. Fish. Aquat. Sci. 48 (5), 875-883.

Walker, S.E., et al., 2004. Polycyclic aromatic hydrocarbons in a highly industrialized urban estuary: inventories and trends. Environ. Toxicol. Chem. 23 (11), 2655-2664.
Yanagida, G.K., et al., 2012. Polycyclic aromatic hydrocarbons and risk to threatened and endangered chinook salmon in the lower Columbia river estuary. Arch. Environ. Contam. Toxicol. 62 (2), 282-295.

Yang, Z.F., et al., 2011. One-hundred-year sedimentary record of polycyclic aromatic hydrocarbons in urban lake sediments from Wuhan, Central China. Water Air Soil Pollut. 217 (1-4), 577-587. 